\title{
Drought-induced proline synthesis depends on root-to-shoot communication mediated by light perception
}

\author{
D. C. Ferreira Júnior ${ }^{1}$ (D) L. A. Gaion ${ }^{1}$ (I) - G. S. Sousa Júnior ${ }^{1}$ - D. M. M. Santos ${ }^{1}$ (D) R. F. Carvalho ${ }^{1}$
}

Received: 3 August 2017 / Revised: 2 October 2017 / Accepted: 9 December 2017 / Published online: 15 December 2017

(c) Franciszek Górski Institute of Plant Physiology, Polish Academy of Sciences, Kraków 2017

\begin{abstract}
Proline accumulation in roots and shoots is one of the most evident responses to environmental stresses such as drought, which is currently one of the main threats for agriculture. Based on this response, in this work, we hypothesize that proline accumulation is dependent on root-to-shoot communication through light perception. Thus, we used exaggerated light response $(\mathrm{hpl}$ ) and phytochrome-deficient $(\mathrm{au})$ mutants of tomato, which were combined through self-grafting and reciprocal grafting and subjected to drought stress, for posterior determination of shoot and root growth and proline content. Lightaffected proline metabolism, as $h p l$, had the highest accumulation, while au presented the lowest proline values. Reciprocal grafting showed that $h p l$ and MT as scion or rootstock improved MT and $a u$ proline content, respectively, indicating shoot-to-root and root-to-shoot communication modulate the metabolism of this compatible osmolyte. Dry weight, leaf area, and root area presented similar patterns to proline content, indicating the importance of this compound for plant growth under stress conditions. These results provide a new perspective on light mediation of long-distance proline translocation in stressed plants.
\end{abstract}

Keywords Phytochromes $\cdot$ Compatible osmolyte $\cdot$ Drought stress $\cdot$ Light signaling

\section{Introduction}

One of the main strategies for drought tolerance in plants is the production of compatible osmolytes, such as free proline, an amino acid that benefits plants by maintaining ideal osmotic conditions and as a non-enzymatic antioxidant agent (Rejeb et al. 2014; Fillipou et al. 2014). Proline synthesis and accumulation are regulated by several environmental factors, including light (Dong et al. 2014; Fichman et al. 2015; Feng et al. 2016). However, the underlying mechanisms of proline biosynthesis mediated by light are still poorly understood, especially under drought stress. An alternative to further comprehension of these pathways is the use of photomorphogenic mutants, which allows the study

Communicated by R. Aroca.

R. F. Carvalho

rfcarval@fcav.unesp.br

1 School of Agricultural and Veterinarian Sciences, São Paulo State University (Unesp), Via de Acesso Prof. Paulo Donato Castellane, Jaboticabal 14884900, Brazil of phytochromes and their involvement in light perception and signaling in plants (Kendrick et al. 1997).

As leaves are considered the main site for proline synthesis (Bojórquez-Quintal et al. 2014), it is speculated that this amino acid can be transported from shoots to roots for osmotic regulation, growth, and other functions (Girousse et al. 1996; Sharma and Dietz 2006; Bundig et al. 2016). Nevertheless, it is still unclear how light perception by shoots really influences root proline homeostasis, which supports root growth under stress conditions and, consequently, water and nutrient uptake (Bundig et al. 2016). For this purpose, this work was carried out with grafted photomorphogenic tomato mutants to elucidate the relationship between shoots and roots on drought-induced proline accumulation.

\section{Materials and methods}

Seeds of tomato (Solanum lycopersicum L.) mutants aurea or $a u$ (phytochrome-deficient) (Muramoto et al. 2005) and high pigment 1 or $h p l$, with enhanced responses to light (Liu et al. 2004), as well as its near isogenic line cv MicroTom (MT) were germinated in plastic trays containing a 
mixture of 1:1 (by volume) commercial pot mix (BioPlant, Brazil) and vermiculite. Fifteen days after sowing, seedlings were transferred to pots filled with the same sowing mixture. Grafting was then performed with the splice method combining MT, $a u$ and $h p l$ in self- and reciprocal grafting combinations (MT/MT, au/au, hpl/hpl, MT/au, au/MT, $\mathrm{MT} / h p 1$, and $h p l / \mathrm{MT}$ ) with the first genotype indicating the scion and the second the rootstock. Grafted plants were immediately placed in a moist chamber and remained there during 15 days (i.e until complete healing of the grafting region). After this period, they were transferred to a greenhouse with average mean temperature of $23.2^{\circ} \mathrm{C}$ and relative humidity of $77 \%$. All plants were watered daily for 1 week, maintaining the maximum holding capacity of the substrate, and then, irrigation was suspended for some of the pots, while daily watering was continued for the control plants for another 7 days. After this period under the respective growth conditions, well-watered and drought-stressed plants were harvested for analysis.

Leaf area was measured using an Image Analysis System (Delta-T Devices, Cambridge, UK), whereas root area was measured using a Hewlett Packard 125C scanner, and then, the image of each plant was analyzed by the Delta-T Scan software. After this, they were oven-dried at $60^{\circ} \mathrm{C}$ for $72 \mathrm{~h}$. Plant dry weight was determined using an analytical balance (Denver Instrument Company AA-200).

Free proline content was determined according to Bates et al. (1973). Root and shoot samples $(0.5 \mathrm{~g})$ from each group were homogenized in $3 \%(\mathrm{w} / \mathrm{v})$ sulfosalicylic acid and the homogenate filtered through filter paper. After the addition of ninhydrin and glacial acetic acid, the resulting mixture was heated at $100{ }^{\circ} \mathrm{C}$ for $1 \mathrm{~h}$ in a water bath. The reaction was then interrupted by immersing the tubes in an ice bath. The mixture was extracted with $4 \mathrm{~mL}$ of toluene, and the absorbance of the solution was read at $520 \mathrm{~nm}$ in a spectrophotometer. The results were expressed as $\mu \mathrm{mol}$ proline $\mathrm{g}^{-1} \mathrm{FW}$.

The experimental design was completely randomized, with three replicates in a $7 \times 2$ factorial scheme representing seven combinations of grafting and two conditions (wellwatered and drought stress). Data were subjected to analysis of variance (ANOVA), and means were compared using Tukey's HSD test (at $p \leq 0.05$ ).

\section{Results and discussion}

When well-watered, all self-grafted plants (MT/MT, au/au, and $h p l / h p l)$ exhibited similar proline accumulations in shoots and roots. Furthermore, we observed that scion proline content in well-watered conditions was not affected by different rootstocks when compared to the respective scion genotypes of self-grafted plants (Fig. 1a). Nevertheless, MT scions showed higher proline accumulation when grafted onto $h p l$ than onto $a u$ rootstock (Fig. 1a). After water stress exposure, there was an evident increase of shoot and root proline contents, evidencing higher and lower enhancement in self-grafted $h p l / h p l$ and $a u / a u$, respectively, when
Fig. 1 Proline content in shoots (a) and roots (b) of grafted photomorphogenic tomato mutants grown in well-hydrated or droughtstressed condition. The same lowercase letter within hydric conditions and the same capital letter within grafting schemes do not significantly differ from each other by Tukey's HSD test $(p<0.05)$

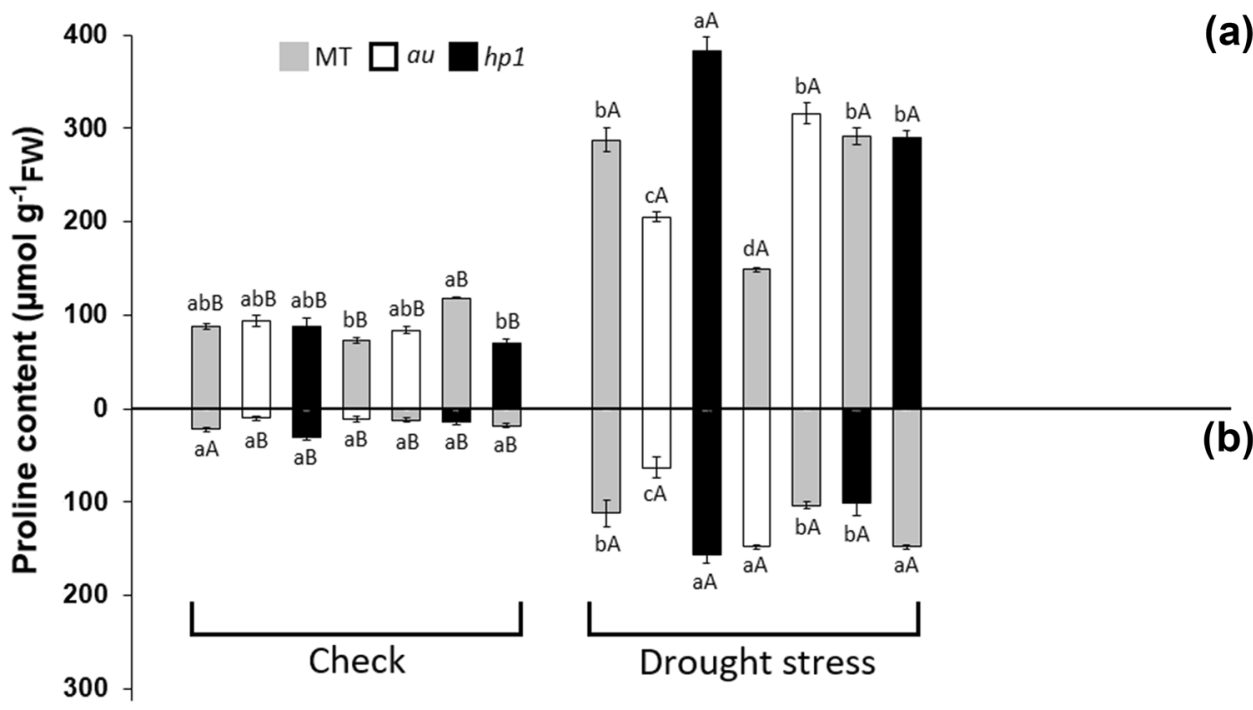


compared to MT/MT (Fig. 1a), indicating the importance of light signaling for proline accumulation during drought stress. Indeed, it is known that light influences proline levels through positive regulation of $\Delta^{1}$-pyrroline-5-carboxylate synthase (P5CS), a key enzyme of the proline biosynthesis pathway (Ábrahám et al. 2003), and also inhibits proline dehydrogenase (PDH), which catalyzes proline degradation (Feng et al. 2016). Therefore, the exaggerated light response in $h p l$ and deficient light perception in $a u$, specifically through the phytochromes, could explain their greater and lower respective accumulations of proline under water deprivation. However, the physiological and biochemical pathways through which $a u$ and $h p l$ can affect proline metabolism seem to be complex. For example, it has been reported that $a u$ has higher antioxidant enzyme activity under drought stress (Alves et al. 2016), which may be a necessity due to lower proline accumulation. Monteiro et al. (2012) also reported that $h p l$ has higher transpiration even outside of stressful conditions, a condition in which higher proline content could be helpful against excessive water loss.

Furthermore, MT grafted onto au resulted in higher proline content in the latter genotype when compared to selfgrafted $a u / a u$ (Fig. 1b). In addition, when $h p l$ was used as scion, it improved proline accumulation in MT rootstock. On the other hand, the MT and $a u$ scions reduced proline contents in $h p l$ and MT rootstocks, respectively. Together, these results indicate a positive light-dependent shoot-toroot communication regarding proline accumulation, possibly due to long-distance transport of this amino acid. Rootstock also had a noticeable influence on scion proline, indicating that root-to-shoot communication may also occur during drought stress modulation of proline biosynthesis.

To evaluate how the differential proline accumulation due to signaling between root and shoot affected plant growth, we assessed leaf and root area, which are important descriptive traits of drought tolerance (Comas et al. 2013; Scoffoni et al. 2014). Considering self-grafted plants, both MT/MT and hpl/hpl had similar leaf areas, while au/au exhibited smaller leaves under well-watered condition; nevertheless, grafting with $h p l$ and $a u$ mutants did not affect MT scion leaf area (Fig. 2a). In the same condition, MT/MT presented the largest root area, followed by $h p l / h p l$ and $a u / a u$, among self-grafted plants (Fig. 2b). Furthermore, MT root area was positively affected by the $h p 1$ scion; likewise, the MT scion increased the root areas of $a u$ and $h p l$. Evidently, irrigation withholding resulted in smaller leaves in almost all treatments (Fig. 2a). Furthermore, unlike in control conditions, $h p l / h p l$ exhibited the largest root area under water-limiting conditions among self-grafted plants, followed by MT/MT and au/au (Fig. 2b). A smaller root area was observed when the $a u$ scion was grafted onto MT rootstock, while the $h p l$ scion improved MT root growth compared to the self-grafted value. Although the $h p l$ root system was not affected by the MT scion, MT in turn when employed in the MT/au combination improved the $a u$ root system. Interestingly, these results were similar to the proline content observations. As a compatible osmolyte, proline can reduce cell osmotic potential under water deficit and help to preserve turgor, a key factor for cell growth and enlargement (Chen et al. 2015) and consequently for leaf and root expansion.

Shoot dry weight, among self-grafted plants, exhibited the same pattern as leaf area, meaning that MT/MT and $h p 1 / h p 1$ displayed higher values than $a u / a u$, under both well-watered and drought conditions (Fig. 2c). Despite this clear difference between self-grafted plants, there was no distinction in the reciprocal-grafted ones in the absence of stress (Fig. 2d). Regarding root dry weight (Fig. 2d), in control conditions, there was no difference between grafted plants. On the other hand, water deprivation impaired dry mass accumulation of roots in almost all plants. All self-grafted plants showed a similar root dry weight. Nevertheless, although MT root dry weight was not affected by the scion, it showed enhanced $a u$ root growth after drought stress exposure. Drought stress also modified shoot dry weight responses; although the $a u$ rootstock did not influence shoot dry weight accumulation in MT, the $h p l$ rootstock improved this parameter in the MT scion. In addition, when used as rootstock, MT increased the shoot dry weight of the $a u$ scion under drought stress. These data reinforce our evidence of root-to-shoot and shoot-to-root communication on proline biosynthesis, considering that this amino acid helps drought-stressed plants to accumulate dry weight through stabilization of several metabolic processes (Rejeb et al. 2014). However, all treatments exhibited a reduction in shoot dry weight, except $a u / \mathrm{MT}$, suggesting that enhanced proline levels are not sufficient to provide drought tolerance.

In this work, we found that the enhanced response to light in $h p l$ induced higher proline accumulation in both shoot and root in $h p l / h p l$ self-grafted plants in comparison with MT/MT. Furthermore, self-grafted plants of $a u$, deficient in phytochrome chromophores (and consequently with impaired phytochrome function), exhibited lower proline content overall. Together, these results illustrate the importance of phytochrome-mediated light perception for proline biosynthesis. In addition, our results provide insights into both shoot-to-root and root-to-shoot signaling 


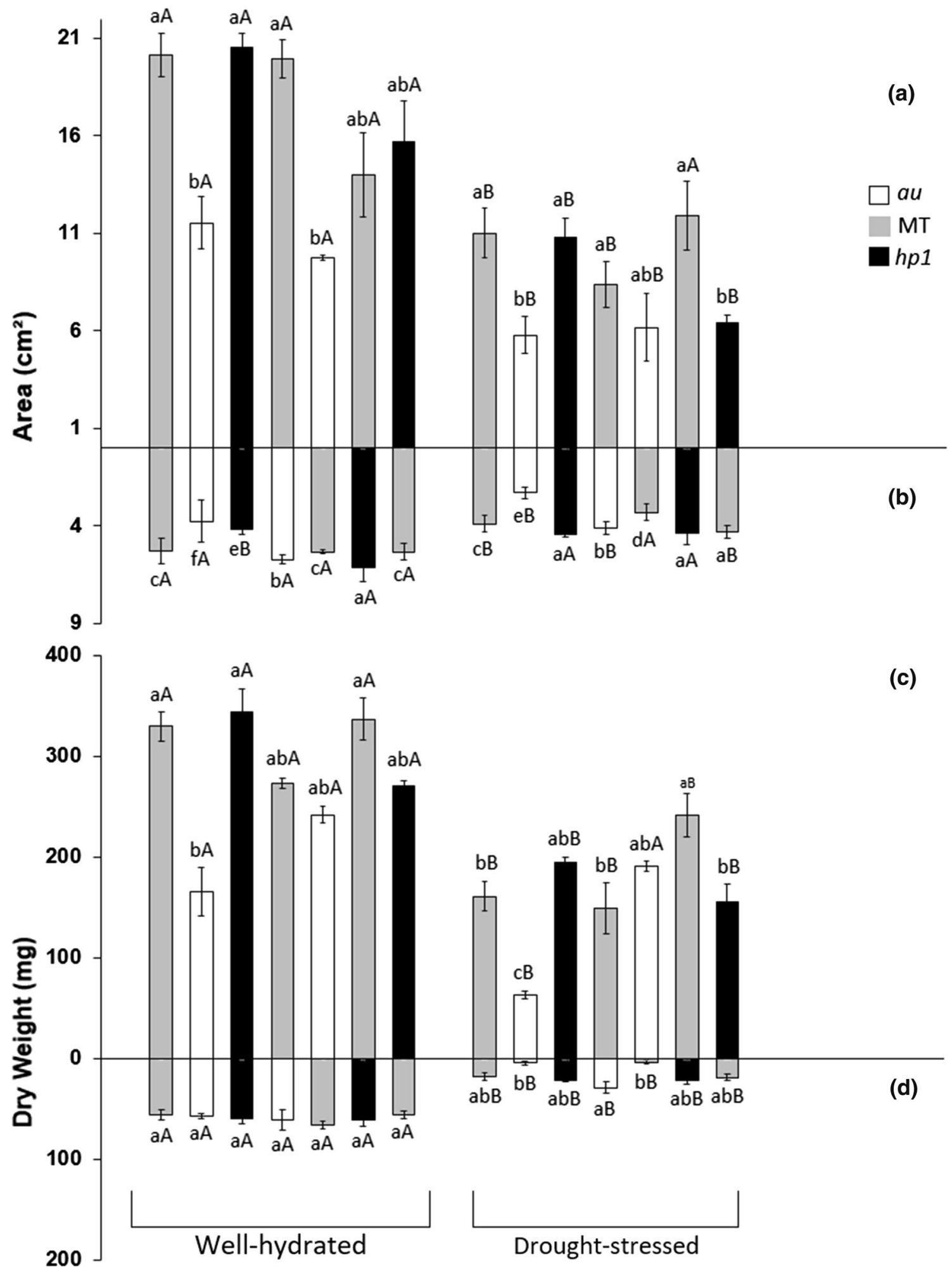

Fig. 2 Leaf and root area (a, b, respectively) and shoot and root dry weight (c, $\mathbf{d}$, respectively) of grafted photomorphogenic tomato mutants grown in well-hydrated or drought-stressed condition. The

same lowercase letter within hydric conditions and the same capital letter within grafting schemes do not significantly differ from each other by Tukey's HSD test $(p<0.05)$ 
in light-controlled proline biosynthesis under water stress and show that the amplification of light signaling could favor adaptation to drought events.

Author contribution statement RFC and DMMS have contributed in the conception and design of this work, and DCFJ, LAG, and GSSJ have contributed in the analysis and interpretation of the data, as well as the writing of the manuscript.

\section{References}

Ábrahám E, Rigó G, Szekély G, Nagy R, Koncz C, Szabados L (2003) Light-dependent induction of proline biosynthesis by abscisic acid and salt stress is inhibited by brassinosteroid in Arabidopsis. Plant Mol Biol 51:363-372. https://doi.org/10.1023/A:1022043000516

Alves FRR, Melo HC, Crispim-Filho AJ, Costa AC, Nascimento RJT, Carvalho RF (2016) Physiological and biochemical responses of photomorphogenic tomato mutants (cv. Micro-Tom) under water withholding. Acta Physiol Plant 38:155-158. https://doi. org/10.1007/s11738-016-2169-8

Bates LS, Waldren RP, Teare ID (1973) Rapid determination of free proline for water-stress studies. Plant Soil 39:205-207. https://doi. org/10.1007/BF00018060

Bojórquez-Quintal E, Valrde-Buendía A, Ku-González A, CarilloPech M, Ortega-Camacho D, Echevarría-Machado I, Pottosin I, Martínez-Estévez M (2014) Mechanisms of salt tolerance in habanero pepper plants (Capsicum chinense Jacq.): proline accumulation, ions dynamics and sodium root-shoot partition and compartmentation. Front Plant Sci 5:605. https://doi.org/10.3389/ fpls.2014.00605

Bundig C, Vu TH, Meise P, Seddig S, Schum A, Winkelmann T (2016) Variability in osmotic stress tolerance of starch potato genotypes (Solanum tuberosum L.) as revealed by an in vitro screening: role of proline, osmotic adjustment and drought response in pot trials. J Agron Crop Sci 203:206-218. https://doi.org/10.1111/jac.12186

Chen LY, Shi DQ, Zhang WJ, Tang ZS, Liu J, Yang WC (2015) The Arabidopsis alkaline ceramidase TOD1 is a key turgor pressure regulator in plant cells. Nat Commun 6:6030. https://doi. org/10.1038/ncomms7030

Comas LH, Becker SR, Cruz VMV, Byrne PF, Dierig DA (2013) Root traits contributing to plant productivity under drought. Front Plant Sci 4:442. https://doi.org/10.3389/fpls.2013.00442

Dong C, Fu Y, Liu G, Liu H (2014) Low light intensity effects on the growth, photosynthetic characteristics, antioxidant capacity, yield and quality of wheat (Triticum aestivum L.) at different growth stages in BLSS. Adv Space Res 53:1557-1566. https:// doi.org/10.1016/j.asr.2014.02.004

Feng XJ, Li JR, Qi SL, Lin QF, Jin JB, Hua XJ (2016) Light affects salt stress-induced transcriptional memory of P5CS1 in Arabidopsis. Proc Natl Acad Sci USA 113:8335-8343. https://doi.org/10.1073/ pnas.1610670114

Fichman Y, Gerdes SY, Kovács H, Szabados L, Zilberstein A, Csonka LN (2015) Evolution of proline biosynthesis: enzymology, bioinformatics, genetics, and transcriptional regulation. Biol Rev Camb Philos Soc 90:1065-1099. https://doi.org/10.1111/brv.12146

Fillipou P, Bouchagier P, Skotti E, Fotopoulos V (2014) Proline and reactive oxygen/nitrogen species metabolism is involved in the tolerant response of the invasive plant species Ailanthus altissima to drought and salinity. Environ Exp Bot J 97:1-10. https://doi. org/10.1016/j.envexpbot.2013.09.010

Girousse C, Bournoville R, Bonnemain JL (1996) Water deficitinduced changes in concentrations in proline and some other amino acids in the phloem sap of alfalfa. Plant Physiol 111:109113. https://doi.org/10.1104/pp.111.1.109

Kendrick RE, Kerckhoffs LHJ, Van Tuinen A, Koornneef M (1997) Photomorphogenic mutants of tomato. Plant Cell Environ 20:746751. https://doi.org/10.1046/j.1365-3040.1997.d01-109.x

Liu YS, Roof S, Ye ZB, Barry C, van Tuinen A, Vrebalov J, Bowler C, Giovannoni J (2004) Manipulation of light signal transduction as a means of modifying fruit nutritional quality in tomato. Proc Natl Acad Sci USA 101:9897-9902. https://doi.org/10.1073/ pnas.0400935101

Monteiro CC, Rolão MB, Franco MR, Peters LP, Cia MC, Capaldi FR, Carvalho RF, Gratão PL, Rossi ML, Martinelli AP, Peres LEP, Azevedo RA (2012) Biochemical and histological characterization of tomato mutants. An Acad Bras Cienc 84:573-585. https://doi. org/10.1590/S0001-37652012005000022

Muramoto T, Kami C, Kataoka H, Iwata N, Linley PJ, Mukougawa K, Yokota A, Kohchi T (2005) The tomato photomorphogenetic mutant, aurea, is deficient in phytochromobilin synthase for phytochrome chromophore biosynthesis. Plant Cell Physiol 46:661665. https://doi.org/10.1093/pcp/pci062

Rejeb KB, Abdelly C, Savouré A (2014) How reactive oxygen species and proline face stress together. Plant Physiol Biochem 80:278284. https://doi.org/10.1016/j.plaphy.2014.04.007

Scoffoni C, Vuong C, Diep S, Cochard H, Sack L (2014) Leaf shrinkage with dehydration: coordination with hydraulic vulnerability and drought tolerance. Plant Physiol 164:1772-1788. https://doi. org/10.1104/pp.113.221424

Sharma SS, Dietz KJ (2006) The significance of amino acids and amino acid derived molecules in plant responses and adaptation to heavy metal stress. J Exp Bot 57:711-726. https://doi.org/10.1093/jxb/ erj073 